\title{
FEMINILIDADES E MASCULINIDADES NA PRIMEIRA TEMPORADA DA SÉRIE ANIMADA STEVEN UNIVERSO
}

\author{
FEMININITIES AND MASCULITIES IN THE FIRST \\ SEASON OF STEVEN UNIVERSE ANIMATED SERIE
}

\author{
Constantina Xavier Filha ${ }^{1}$ \\ Victória Nobica Marques do Nascimento ${ }^{2}$
}

\section{RESUMO}

A pesquisa, que descreveremos neste artigo, teve por objetivo discutir e problematizar as feminilidades e masculinidades veiculadas na primeira temporada da série animada Steven Universo. A problemática que norteou a pesquisa foi: Quais tipos de feminilidades e masculinidades a série animada Steven Universo apresenta? A pesquisa baseou-se nas metodologias pós-críticas em educação e seguiu os preceitos dos Estudos de Gênero e Sexualidades e Educação, fazendo uso do percurso teórico metodológico da etnografia de tela. Utilizamos os conceitos gênero, identidade de gênero e sexual, normalização, feminilidades e masculinidades, pedagogias de gênero e sexualidade e Pedagogias Culturais. Para organizar nossas discussões fizemos dois agrupamentos nas discussões encontradas na análise dos episódios: "Personagens femininas" e "Personagens masculinas", tendo como critério o gênero com o qual o/a telespectador/a identifica a personagem. Com base nos nossos pressupostos teóricos foi possível pensar nas discussões e problematizações referentes à nossa problemática, compreendendo a necessidade de se entender as formas de educações e pedagogias que ocorrem para além das instituições educativas.

Palavras-chave: Educação. Feminilidades. Masculinidades. Gênero no desenho animado.

\begin{abstract}
The research wich we are going to describe in this article aims to discuss and to problematize the femininities and masculities served in the first season of Steven Universe animated serie. The problematic that has norted our research was: Wich type of femininities and masculinities the animated serie Steven Universe presents? The research was based in the post-critic metodologies in education and follow the precepts of Gender and Sexualities Studies and Education, using the metodologic rout of screen ethnography. We use the concepts of gender, gender and sexual identity, normalization, femininities and masculinities, gender and sexual pedagogies and Cultural Pedagogies. To organize our discussions we made two groups, find in the analysis of the episodes: "Famale characters" and "Male characters", having as standard the gender with wich the viewer identifies the character. Based on our teorics precepts was possible to think in the discussions and problematizations regarding our problematic, realizing the necessity of understand the forms of education and pedagogies that happen beyond the educational institutions.
\end{abstract}

Keywords: Education. Femininities. Masculinities. Gender in cartoon.

\footnotetext{
${ }^{1}$ Graduada em Pedagogia pela Faculdade Unidas Católicas de Mato Grosso (1990), com mestrado em Educação pela Universidade Federal de Mato Grosso do Sul (1998), doutorado em Educação pela Universidade de São Paulo - FEUSP (2005) e realização de Pós-Doutorado pela Unicamp (2014/2015). Atualmente é professora Associada da Universidade Federal do Mato Grosso do Sul - UFMS atuando no curso de Pedagogia e no Programa de Pós-Graduação em Educação.E-mail: tinaxav@terra.com.br.

${ }^{2}$ Graduada em Pedagogia pela Universidade Federal de Mato Grosso do Sul (UFMS).
} 


\section{Revista}

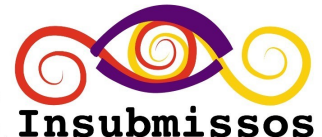

\section{INTRODUÇÃO}

O presente artigo tem por objetivo descrever e questionar os tipos de feminilidade e masculinidade veiculados na primeira temporada da série animada Steven Universo. A pesquisa teve por tema a questão gênero no desenho animado. Seu objetivo foi estudar os padrões ali apresentados com o intuito de investigar se tais manifestações correspondem a formas hegemônicas, ou se delas diferem.

Este tema começou a ser pensado no decorrer da atuação no projeto de extensão "Produção de filme de animação com crianças-2016" (UFMS), bem como na participação no Grupo de Estudos e Pesquisas em Sexualidades, Educação e Gênero (GEPSEX), coordenado pela mesma professora na referida instituição de ensino superior. Além disso, a fascinação por cinema de animação nos motivou a estudar gênero no desenho animado.

O desejo inicial era escolher como fonte uma série que fosse de nosso interesse e conhecimento. Para a escolha, estabelecemos alguns critérios, a saber:

a) estar em exibição no momento da pesquisa;

b) apresentar modelos de feminilidade e masculinidade diferentes dos comumente aceitos como normais e culturalmente desejáveis; e

c) ser uma série de grande audiência.

A partir desses critérios, foi selecionado o desenho animado Steven Universo, determinando-se como objeto de investigação os tipos de "feminilidade e masculinidade na série animada Steven Universo".

A partir do tema e da definição do objeto, construímos a seguinte problemática: "Que tipos de masculinidade e feminilidade a série animada Steven Universo apresenta?”

Steven Universo é uma animação criada pela estadunidense Rebecca Sugar, a primeira mulher a criar uma série para o canal Cartoon Network. A série estreou nos Estados Unidos no dia 4 de novembro de 2013 e, no Brasil, dia 7 de abril de 2014. A história se passa na cidade fictícia de Beach City, onde Steven, o protagonista, mora com as Crystal Gems, um grupo de alienígenas humanoides da raça Gem, que se rebelou contra seu planeta natal (Homeworld) e luta para proteger a terra dos perigos vindos de lá. Steven é filho de Greg, um 
humano, com Rose Quartz, a antiga líder das Crystal Gems, que abriu mão de seu corpo físico para dar à luz Steven. Ao nascer, o menino herdou a pedra preciosa (chamada no desenho de "Gem") de sua mãe, um quartzo rosa, que lhe confere super-força, poder de flutuar, poderes mágicos como a invocação de armas que, no caso de Steven, é um escudo. A história se desenvolve com Steven aprendendo a controlar seus poderes e ajudando as Crystal Gems a proteger a Terra enquanto convive com os/as moradores/as da cidade de Beach City, ajudando-os/as nas mais diversas situações cotidianas.

A pesquisa baseou-se nas metodologias de pesquisas pós-críticas em educação e faz uso do percurso teórico metodológico da etnografia de tela. Nosso referencial teórico partiu de Estudos Culturais e Estudos de Gênero e Sexualidades. Para seu desenvolvimento, recorremos a autores/as como Guacira Lopes Louro (2008), Jane Felipe (1995) e Tomaz Tadeu da Silva (2000).

O presente artigo está dividido em três partes. Na primeira, denominada "Pressupostos teórico-metodológicos de análise e discussões dos episódios", apresentamos os caminhos metodológicos utilizados neste trabalho. $\mathrm{Na}$ segunda, chamada "Pressupostos teóricos utilizados nas discussões da série animada", expomos os conceitos que embasaram a pesquisa. $\mathrm{Na}$ terceira, denominada "Feminilidades e masculinidades em Steven Universo", apresentamos as discussões teórico-metodológicas dos episódios escolhidos.

\section{PRESSUPOSTOS TEÓRICO-METODOLÓGICOS DE ANÁLISE E DISCUSSÃo DOS EPISÓDIOS}

Neste tópico, apresentamos os caminhos teórico-metodológicos utilizados para a realização de nossa pesquisa, que tem por base as metodologias pós-críticas em educação. Seguimos esse caminho pela oportunidade que ele nos oferece de questionar o que já sabemos, para rever o que já foi produzido sobre o mesmo tema e problematizar nosso objeto. De acordo com Mayer e Paraíso, “[...] o mais potente desses modos de pesquisar é a alegria de ziguezaguear. Movimentamo-nos ziguezagueando no espaço entre nossos objetos de investigação e aquilo que já foi produzido sobre ele, para aí estranhar, questionar, desconfiar" (2012, p. 17). 
A partir de tais pressupostos, permitimo-nos "ziguezaguear" entre o nosso tema, gênero no desenho animado, e o que já foi produzido sobre ele, para então discutir e problematizar nosso objeto, os tipos de feminilidade e masculinidade na primeira temporada da série animada Steven Universo, sem a pretensão de produzir verdades inquestionáveis, para então incluir novos pontos de vista, novas formas de olhar e perceber algo que não está dado.

Seguindo os referidos pressupostos:

Entendemos metodologia como um certo modo de perguntar, de interrogar, de formular questões e construir problemas de pesquisa que é articulado a um conjunto de procedimentos [...] de "produção" de informação - e de estratégias de descrição e análise (MAYER; PARAÍSO, 2012, p. 16).

A pesquisa pós-crítica, conforme anunciado pelas autoras referidas, ocorre com sucessivas interrogações, com a possibilidade de construir novos problemas, buscando formular novas questões e interrogações para descrever e analisar o objeto da pesquisa, produzindo novas informações e problematizações sobre ele.

Com tais metodologias aplicadas ao campo da educação, segundo Meyer e Paraíso:

\begin{abstract}
Afastamo-nos daquilo que é rígido, das essências, das convicções, dos universais, da tarefa de prescrever e de todos os conceitos e pensamentos que não nos ajudam a construir imagens de pensamentos potentes para interrogar e descrever-analisar nosso objeto. Aproximamo-nos daqueles pensamentos que nos movem, colocam em xeque nossas verdades e nos auxiliam a encontrar caminhos para responder nossas interrogações. Movimentamo-nos para impedir a "paralisia" das informações que produzimos e que precisamos descrever-analisar. Movimentamo-nos, em síntese, para multiplicar sentidos, formas e lutas. (2012, p. 16-17).
\end{abstract}

Como já salientado, não tivemos a intenção de produzir verdades sobre nosso objeto, nem responder a perguntas de forma universal e essencialista; nosso desejo, seguindo os caminhos propostos pelos pressupostos desse pressuposto de pesquisa, foi caminhar entre perguntas e interrogações e produzir informações e discussões, descrevendo-analisandoproblematizando o tema que estudamos.

A pesquisa utilizou o percurso teórico metodológico da etnografia de tela para analisar o mencionado objeto. Essa etnografia faz parte dos estudos de recepção, definidos por Carmen Silva Rial: 


\section{novetwe \\ Debates Insubmissos}

Nos estudos de recepção, a mensagem é vista como uma construção de signos que, na interação com os receptores, ganham significados. A ênfase não está mais no emissor (sua intenção não prevalece na definição do que é a mensagem), no meio, ou no texto, mas em suas possíveis leituras. (2004, p. 33).

A autora esclarece que o mais importante nos estudos de recepção são as possíveis leituras do texto midiático a serem feitas pela audiência, independente da intenção do/a emissor/a na produção do texto. A mensagem do texto midiático ganha significado na interação com seu/sua receptor/a. A pesquisa ganha novos olhares desde que haja interação com a mídia, ou, em nosso caso, com os episódios da série animada. Com isso - interação e discussão com as questões que propomos e outras que serão construídas no decorrer da imersão-análise -, novos olhares foram criados.

Segundo Carmen Silva Rial, que cunhou o termo etnografia de tela, esse percurso teórico metodológico constitui:

[...] uma metodologia que transporta para o estudo do texto da mídia procedimentos próprios da pesquisa antropológica, como a longa imersão do pesquisador no campo (no caso, em frente à televisão), a observação sistemática e o seu registro metódico em caderno de campo, etc.; outras próprias da crítica cinematográfica (análise de planos, de movimentos de câmera, de opções de montagem, enfim, da linguagem cinematográfica e suas significações) e outras próprias da análise de discurso. (RIAL, 2004, p. 30-31).

A etnografia de tela é um percurso teórico-metodológico que permite ressignificar as técnicas da pesquisa antropológica-etnográfica no estudo dos textos midiáticos, combinadas com ferramentas de estudo cinematográfico, exigindo que o/a pesquisador/a imerja na tela como seu campo de estudo, tal como o/a estudioso/a etnográfico imergiria no campo social.

Segundo Balestrin e Soares, os procedimentos necessários para realização da etnografia de tela são:

[...] longo período de contato com o campo (neste caso, com a tela); observação sistemática e variada (assistir ao filme/programa de diferentes modos - sem interrupção, com pausas para registro, assistindo aos extras); registro em caderno de campo (tanto da descrição das cenas fílmicas e/ou televisivas, como de questões e pontos que parecem potencialmente interessantes para a análise); escolha de cenas para a análise propriamente dita. (2012, p. 93). 
As autoras elucidam os passos importantes para a realização de uma pesquisa usando a metodologia da etnografia de tela, como a longa imersão no campo de pesquisa, o registro em caderno de campo e a escolha das cenas para a análise. Estes aspectos foram relevantes para podermos estabelecer nosso caminho metodológico ao adotar os procedimentos da etnografia de tela, algo ainda novo, porém instigante para a análise e discussão de artefatos culturais. A seguir, explicitamos os caminhos metodológicos trilhados para a realização da investigação.

Para tal realização, da qual se origina este artigo, escolhemos cinco episódios da primeira temporada da série animada Steven Universo, a saber: "O brilho da pedra" (episódio 1); "O canhão de laser" (episódio 2); "Dedos de gatos" (episódio 6); "A mulher gigante" (episódio 12) e "Negociando com o Cebola" (episódio 15).

O critério de seleção desses cinco episódios foi o de serem os de maior audiência dentre os demais da primeira temporada.

Os citados episódios representaram a fonte de nossa pesquisa. A partir do referencial teórico-metodológico, elaboramos fichas de análise contendo informações técnicas sobre o episódio, descrição física e de conduta das personagens femininas e masculinas apresentadas no episódio analisado, para enfim conseguir visualizar de forma geral as informações obtidas no exercício de assisti-los.

As fichas de análise continham as seguintes informações técnicas: título original do episódio (EN); título traduzido (PT-BR); número do episódio; duração; roteiro; gênero roteirista(s); resumo da história; música no episódio (em caso de resposta positiva, inclusão da letra da música). Na ficha também havia espaço para informações sobre as personagens: nome da personagem; gênero com o qual a personagem se identifica; gênero com o qual o/a telespectador/a a identifica; características físicas; vestimentas e descrição de conduta.

Por intermédio de tais fichas, foi possível analisar as características físicas e atitudinais das personagens masculinas e femininas do desenho animado, problematizar as formas de feminilidade e masculinidade apresentadas na primeira temporada da série e questionar se essas formas representam ou não ruptura com o padrão das normas de gênero. 


\section{PRESSUPOSTOS TEÓRICOS UTILIZADOS NAS DISCUSSÕES DA SÉRIE} ANIMADA

Contextualizamos, neste tópico, os principais conceitos que nortearam a pesquisa. A partir dos Estudos Culturais, dos Estudos de Gênero e de Sexualidade, recorremos aos conceitos de gênero, identidade de gênero e sexual, normatização, tipos de feminilidade e masculinidade, pedagogias de gênero e sexualidade e pedagogias culturais para as discussões e problematizações do estudo. Para isso, utilizaremos autores/as como Guacira Lopes Louro (2008), Jane Felipe (1995) e Tomaz Tadeu da Silva (2000), dentre outros/as.

Destacaremos, em primeiro lugar, o conceito de gênero. Segundo Guacira Lopes Louro (2008), gênero pode ser explicado como:

[...] constituinte da identidade de sujeitos. [...] compreendemos os sujeitos como tendo identidades plurais, múltiplas; identidades que se transformam, que não são fixas ou permanentes, que podem, até mesmo, ser contraditórias. [...] a ideia é perceber o gênero fazendo parte do sujeito, constituindo-o. (2008, p. 29, grifos da autora).

A autora esclarece que gênero é um dos aspectos que compõem as características dos sujeitos, que são plurais e construídas continuamente com a contribuição de elementos sociais e culturais; além disso, gênero tem caráter fluído, não sendo fixo ou permanente. $O$ gênero faz parte do que é o sujeito, assim como outras características, como raça/etnia e classe social.

Jane Felipe reitera esse raciocínio:

[...] as pesquisas neste campo têm se voltado para o caráter relacional dos gêneros, entendendo que mulheres e homens, meninas e meninos são formados em relação uns com os outros e também no entrecruzamento de outras categorias, como classe social, religião, etnia, nacionalidade, geração. (FELIPE, 1995, p. 4).

A autora mostra que, além de o gênero constituir-se como identidade construída ao longo do tempo e de acordo com a cultura, não é algo fixo, nem acabado; o gênero se constrói na relação com o/a outro/a e com as outras características/identidades do sujeito, permitindonos pensar para além do binarismo de gênero - masculino e feminino -, para outras formas de o constituir, inventando muitos e múltiplos jeitos de ser masculino e feminino, vivendo na fronteira, ou até mesmo negando-o. 


\section{novistet

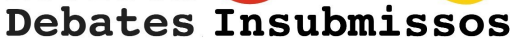

As identidades de gênero são, muitas vezes, normalizadas, sendo definidas conforme as maneiras culturalmente esperadas de ser e agir. Tomaz Tadeu da Silva define o conceito de normalização:

A normalização é um dos processos mais sutis pelos quais o poder se manifesta no campo da identidade e da diferença. Normalizar significa eleger - arbitrariamente uma identidade específica como parâmetro em relação ao qual as outras identidades são avaliadas e hierarquizadas. Normalizar significa atribuir a essa identidade todas as características positivas possíveis, em relação às quais as outras identidades só podem ser avaliadas de forma negativa. (SILVA, 2000, p. 83).

Para o autor, a normalização é um processo sutil e permanente que define uma identidade como parâmetro para se avaliar as outras. Esse processo ocorre quase sempre de forma negativa e hierárquica, ou seja, normalizar é eleger uma identidade como padrão para que as outras existam e sejam julgadas e questionadas.

Como já salientado, as identidades de gênero são construídas de forma relacional, com o/a outro/a e com as outras identidades do sujeito; uma dessas identidades é a sexual, muitas vezes confundida com a identidade de gênero, uma vez que são profundamente interrelacionadas. Guacira Lopes Louro esclarece:

[...] identidades sexuais se constituiriam, pois, através das formas como vivem sua sexualidade, com parceiros/as do mesmo sexo, do sexo oposto, de ambos os sexos ou sem parceiros/as. Por outro lado, os sujeitos também se identificam, social e historicamente, como masculinos ou femininos e assim constroem suas identidades de gênero. (LOURO, 2008, p. 26-27).

A autora elucida a diferença entre identidades sexuais e identidades de gênero, salientando, mais uma vez, o caráter fluído e não determinado dessas identidades, ressaltando a maneira como elas são construídas. Para a autora, identidade de gênero não é o mesmo que identidade sexual. Identidade sexual é a maneira de se relacionar com alguém afetivamente ou a relação do sujeito com o seu desejo por pessoas do mesmo gênero, gênero diferente ou com ambos os gêneros. Há, além dessas, inúmeras outras identidades sexuais, inclusive a assexualidade; no entanto, ficamos com essa definição para fins de análise do nosso objeto.

Bacarin elucida os conceitos de feminilidade e masculinidade:

Os conceitos de masculinidade e feminilidade estão diretamente ligados ao conceito de gênero. No entanto, enquanto gênero é a forma como nos identificamos enquanto mulheres e homens, feminilidades são as formas e possibilidades de vivência do 


\section{novist \\ Debates Insubmissos}

feminino. Esses modos pelos quais vivemos nossas masculinidades e feminilidades são fruto das construções sociais. (BACARIN, 2015, p. 39).

Para a autora, as feminilidades e masculinidades, assim como o gênero, são construídas socialmente, na interação entre os sujeitos, sendo a forma como os indivíduos vivem e expressam o feminino e o masculino. Essas formas são pluralizadas e não têm relação direta com o aspecto biológico do sujeito.

Connel explicita o conceito de masculinidade:

O que se entende por "masculinidade"? Deixem-me oferecer uma definição - breve, mas razoavelmente precisa. A masculinidade é uma configuração de prática em torno da posição dos homens na estrutura das relações de gênero. Existe, normalmente, mais de uma configuração desse tipo em qualquer ordem de gênero de uma sociedade. Em reconhecimento desse fato, tem-se tornado comum falar de "masculinidades". (CONNEL, 1995, p. 188).

Bacarin (2015) expõe o caráter múltiplo das formas de ser homem/menino, e pensamos que, da mesma maneira, existem várias formas de ser mulher/menina; portanto, torna-se necessário falar em "feminilidades". Connel (1995) retifica o pensamento de que as masculinidades são criadas no âmbito social, na interação dos sujeitos. As masculinidades e feminilidades foram conceitos acionados para pensar como as personagens da série animada se constituíram nos roteiros e imagens.

Para pensar sobre os episódios da série Steven Universo, procuramos pensá-los como instrumentos educativos e elementos de pedagogia, não aquela vivenciada nas instituições educativas, mas dos tipos de pedagogia que fazem parte das instituições sociais e abrangem as temáticas de gêneros e sexualidades. Assumimos o conceito de pedagogias de gênero e sexualidade apresentado por Louro:

Aprendemos a viver o gênero e a sexualidade na cultura, através dos discursos repetidos da mídia, da igreja, da ciência e das leis e também, contemporaneamente, através dos discursos dos movimentos sociais e dos múltiplos dispositivos tecnológicos. (LOURO, 2008, p. 22).

Para a autora, diferentes instâncias, grupos sociais e mídias ensinam formas de ser homem e ser mulher, construindo identidades e sujeitos. As formas como devemos nos comportar e ser enquanto homem ou mulher são apontadas pela cultura a partir das inúmeras pedagogias. "Tais pedagogias ensinam, informam, regulam e estabilizam práticas, normas e 
desejos de forma a constituir identidades de gênero e sexualidade que possam dar uma referência 'segura' sobre os indivíduos" (SEVILLA, 2015, p. 2-3).

Para a discussão sobre as pedagogias desenvolvidas pelos mais diversos artefatos culturais, dentre eles a da série animada em análise, necessitamos pensar sobre outro conceito, que é o de pedagogia cultural. Por esse conceito, podemos pensar que a educação pode se desenvolver:

[...] numa variedade de áreas sociais, incluindo mas não se limitando à escola. Áreas pedagógicas são aqueles lugares onde o poder é organizado e difundido, incluindose bibliotecas, TV, cinemas, jornais, revistas, brinquedos, propagandas, videogames, livros, esportes, etc. (STEINBERG; KINCHELOE, 2001, p. 14).

Os Estudos Culturais salientam que a educação não é realizada apenas no ambiente escolar, fazendo uso do conceito de pedagogias culturais, que vem a ser a ideia de que os diferentes artefatos da cultura educam e ensinam formas de ser, produzem os sujeitos. Pedagogias culturais, segundo Tomaz Tadeu da Silva (2000, p. 89), são quaisquer instituições ou dispositivos culturais "que, tal como a escola, estejam envolvidos - em conexão com relações de poder - no processo de transmissão de atitudes e valores [...].”. São instrumentos das pedagogias culturais os filmes, as revistas, a televisão, dentre outros, bem como os episódios de animação, objeto desta pesquisa. Buscar problematiza-los são possibilidades importantes para pensarmos sobre o que se espera para a constituição de sujeitos masculinos e femininos, sobretudo crianças e adolescentes.

\section{FEMINILIDADES E DE MASCULINIDADES EM STEVEN UNIVERSO}

Neste tópico, descreveremos e discutiremos os tipos de feminilidade e masculinidade apresentadas pela série animada Steven Universo, buscando dialogar com os conceitos citados no tópico anterior. A partir do tema e do objeto de nossa pesquisa, construímos a nossa problemática: "Quais os tipos de masculinidade e feminilidade a série animada Steven Universo apresenta?"

Para responder à nossa pergunta, escolhemos cinco episódios da primeira temporada da série para discutir, utilizando como critério de seleção a maior audiência dos episódios 
segundo o site The futon critic $^{3}$, com o objetivo de discutir e problematizar os tipos de feminilidade e masculinidade veiculados na primeira temporada da série animada.

Os cinco episódios selecionados, já destacados, foram: "O brilho da pedra" (episódio 1); "O canhão de laser" (episódio 2); "Dedos de gatos" (episódio 6); "A mulher gigante" (episódio 12); e "Negociando com o Cebola" (episódio 15). Para problematizar mais detidamente as informações contidas nos audiovisuais, elaboramos e preenchemos fichas de análise. A partir do exercício de assistir aos episódios e preencher as fichas, definimos dois agrupamentos: personagens femininas e personagens masculinas de acordo com o gênero com que o/a telespectador/a identifica a personagem.

O presente tópico está dividido em duas partes. Na primeira, "descrição dos episódios a serem discutidos", descrevemos a história dos episódios e suas informações técnicas, como título original do episódio (EN); título traduzido (PT-BR); número do episódio; duração; roteiro; gênero do/a roteirista(s); música (ou não) no episódio e quais personagens aparecem no episódio. A seguir, descrevemos física e atitudinalmente as personagens apresentadas nos cinco episódios.

\subsection{Descrição dos episódios a serem discutidos}

Neste tópico, descrevemos os episódios selecionados para a discussão.

No episódio número 1, "O brilho da pedra", as personagens principais da série são: Steven, Ametista, Garnet e Pérola, que formam o grupo Crystal Gems. Steven ainda não sabe controlar seus poderes e pensa que eles são ativados quando toma sorvete, pois, ao comer o biscoito gatinho, seu biscoito de sorvete favorito, sua pedra começa a brilhar; porém, quando se vê em uma situação de batalha real, ele percebe que talvez seus poderes não funcionem assim e precisa pensar em uma solução que não envolva poderes mágicos. A história se desenvolve, na maior parte do tempo, na casa de Steven e das Crystal Gems; também se desenvolvem cenas na loja "Big rosquinha" e na praia onde fica a casa de Steven.

\footnotetext{
${ }^{3}$ Disponível em: <http://www.thefutoncritic.com>. Acesso em: 15 out. 2017.
} 
O episódio tem 11min32s de duração; seu título original (EN) é "Gem Glow". O roteiro foi escrito por Joe Johnston e Jeff Liu, ambos do gênero masculino. Não há música no episódio e as personagens apresentadas são: Ametista, Garnet, Lars, Pérola, Sadie e Steven.

No episódio número 2, “O canhão de laser”, um olho gigante vindo do espaço ameaça chocar-se com a cidade de Beach City. As Crystal Gems não conseguem destruí-lo de forma alguma, quando se lembram de um canhão de luz que pertenceu a Rose Quartz, antiga líder das Crystal Gems e mãe de Steven, que abriu mão de seu corpo físico para que Steven pudesse nascer. Steven sai à procura do canhão, que pensa estar com o pai, o humano Greg Universo. Steven encontra o canhão que realmente estava em posse de seu pai, quando surge um novo problema: ninguém sabe como ativá-lo. A única que sabia como fazê-lo funcionar era Rose Quartz, que não havia deixado nenhuma instrução de como usá-lo. Steven, em um momento de desespero, profere a frase que era o lema de seu pai: "Se o porco inteiro fosse perfeito, não haveria cachorro quente". Isto faz com que o canhão funcione e emita uma luz laser que destrói o olho gigante que ameaçava a cidade, fazendo Greg se emocionar com a prova de amor deixada por Rose. A maior parte do episódio se passa na praia onde fica a casa de Steven. Lá também acontecem cenas no lava a jato do qual Greg é o dono, em um galpão e na van, também pertencentes a Greg, e pelas ruas da cidade de Beach City.

O episódio tem $11 \mathrm{~min} 32 \mathrm{~s}$ de duração; seu título original (EN) é "Laser Light Cannon". O roteiro foi escrito por Kat Morris e Rebecca Sugar, ambas do gênero feminino. Há uma música no episódio, cantada por Greg, chamada Dirigindo minha van para o seu coração. As personagens apresentadas são: Ametista, Fryman, Garnet, Greg, Pérola e Steven.

No episódio número 6, "Dedos de gato", Steven quer aprender a usar seus poderes de transformação, que toda/o Gem possui. Ele sente vontade de usar esses poderes após ver Ametista desempenhando transformações para realizar brincadeiras. Ao tentar transformar-se em um gato, Steven acaba por transformar apenas um de seus dedos em um gatinho. Ele se sente satisfeito com isso e decide mostrar a seu pai e a todos/as os/as seus/as amigos/as da cidade essa transformação. Ao mostrar seu novo feito, ela acaba transformando todos os seus dedos em gatos. Ele volta para casa e percebe que não consegue realizar nenhuma atividade com seus dedos de gato; então, pede ajuda às Crystal Gems, porém, elas estão saindo em uma 
missão que não pode esperar para resolver tal situação. Steven, então, se vê sozinho e gatinhos começam a aparecer por todo o seu corpo. Ele, então, vai pedir ajuda à única pessoa que restou: seu pai, que, mesmo tendo muito medo de tudo que envolve magia, consegue ajudá-lo a voltar para o seu corpo de antes. A história se passa no lava a jato de Greg, na casa de Steven e no calçadão da praia, onde fica a lanchonete da família Fryman.

O episódio tem $11 \mathrm{~min} 32 \mathrm{~s}$ de duração; seu título original (EN) é “Cat Fingers". O roteiro foi escrito por Hilary Florido, Kat Morris e Rebecca Sugar, do gênero feminino e Ian Jones Quartey, do gênero masculino. Não há música no episódio. As personagens apresentadas são: Ametista, Fryman, Garnet, Greg, Lars, Peedee, Pérola, Prefeito Dewey, Ronaldo, Sadie e Steven.

No episódio número 12, "A mulher gigante", por causa de um jogo de damas, Ametista e Pérola começam uma discussão na frente de Steven. Ametista diz que é por Pérola ser tão "careta" que elas não formam mais a Opal. Steven fica curioso, e pergunta quem é Opal. Elas explicam que se trata de uma nova alienígena, com a forma de uma mulher gigante, que surge quando as duas fundem seus corpos; um poder que toda/o Gem possui. Steven fica muito animado com a possibilidade de ver uma mulher gigante e insiste para que as duas se fundam, mesmo elas deixando claro que fusões só acontecem em situações de perigo mortal. Ao saírem os/as três em uma missão dada por Garnet, Steven é engolido por um pássaro gigante. Então, Ametista e Pérola se fundem, formando a Opal, e proporcionam a Steven a oportunidade de ver uma mulher gigante. A história acontece na praia, na casa de Steven e na Torre Celeste.

O episódio tem 11 min32s de duração; seu título original (EN) é "Giant Woman". O roteiro foi escrito por Joe Johnston e Jeff Liu, ambos do gênero masculino. Há uma música no episódio, cantada por Steven, chamada Mulher gigante. As personagens apresentadas são: Ametista, Garnet, Opal, Pérola e Steven.

No episódio número 15, "Negociando com o Cebola", Steven perde um dos seus C.A.R.A.S., que são figuras de ação colecionáveis. O brinquedo perdido havia sido ganho por Steven em um dia que ele considera muito especial, passado na praia com seu pai. Steven vê que seu colega Cebola possui um brinquedo igual ao que ele perdeu e tenta fazer uma troca 
com ele por um dos C.A.R.A.S. que ele tem repetido em sua coleção. Cebola não aceita a proposta. Steven volta para casa e Ametista lhe dá uma varinha replicadora que ela pegou de Pérola. Ele, então, volta a falar com Cebola e tenta novamente realizar a troca, agora oferecendo mais brinquedos, replicados com a varinha de Pérola. Cebola não aceita e pede a varinha em troca do brinquedo. Steven aceita e vai satisfeito para casa. A cidade, então, começa a ser tomada por uma enorme quantidade de brinquedos replicados por Cebola com a varinha. As Crystal Gems aparecem e tentam resolver o problema tomando de Cebola a varinha, mas sem sucesso. Steven, pegando-o de surpresa, lhe toma a varinha. Depois de resolvida a situação, Steven percebe que o brinquedo que estava com Cebola era o seu, que havia sumido, pois o brinquedo tinha as iniciais de seu nome gravadas embaixo. Cebola havia roubado o boneco de Steven. A história acontece na casa de Steven, na van de Greg, no fliperama e pelas ruas da cidade de Beach City.

O episódio tem 11min32s de duração; seu título original (EN) é "Onion Trade". O roteiro foi escrito por Lammar Abrams, do gênero masculino. Não há música no episódio. As personagens apresentadas são: Ametista, Cebola, Garnet, Greg, Pérola e Steven.

Faremos agora a descrição física e de conduta de todas as personagens apresentadas nos cinco episódios analisados. Organizaremos a lista em ordem alfabética, não por importância das personagens:

- Ametista: Alienígena, que apresenta uma forma que se assemelha à de uma mulher adulta. Tem a pele roxa e longos cabelos lisos e brancos; é baixa e gorda ${ }^{4}$. Carrega uma pedra ametista no peito, de onde convoca sua arma, um chicote preto com duas pontas e pedras roxas nas extremidades. Veste uma blusa regata cinza-escura, com um cinto na cintura e uma calça preta com estrelas cortadas nos joelhos. Usa sapatos brancos. Ametista aparece em cinco dos cinco episódios assistidos e apresenta as seguintes características atitudinais:

\footnotetext{
${ }^{4}$ Usaremos a denominação "gorda/o" sabendo que é um termo carregado de preconceitos; porém, acreditamos na possibilidade de ressignificação dos signos da linguagem. Para isso, recorremos aos estudos de Judith Butler, que afirma que "a temporalidade aberta do signo significa que insultos e termos pejorativos podem vir a se constituir em oportunidades para contramobilizações e reapropiações radicais." (In: SALIN, 2012, p. 159). Neste sentido, o termo passa a ter outra significação, até mesmo política, para questionarmos os ditames dos padrões de beleza e de magreza.
} 
alegre, amistosa, brincalhona, corajosa, descortês, forte, aparentemente irresponsável, determinada, otimista, afetuosa, despreocupada, autoconfiante e preguiçosa.

- Cebola: Menino de aparentemente oito anos; tem a pele branca e os cabelos loiros em um topete. É gordo. Veste uma blusa de frio branca, uma calça vermelha e sapatos de uma cor que se funde com a da calça. Usa um casaco azul amarrado aos ombros. Cebola aparece em um dos cinco episódios assistidos e apresenta as seguintes características atitudinais: descortês e maldoso.

- Fryman: Trata-se de homem e adulto. Tem a pele branca e cabelos amarelos, barba amarela. É alto e musculoso; tem ombros largos. Veste uma camiseta vermelha e uma bermuda, jeans, às quais se sobrepõe um avental branco. Usa uma viseira que mantém seus cabelos para cima. Calça sapatos tipo alpargata amarelos. Fryman aparece em dois dos cinco episódios assistidos e apresenta as seguintes características atitudinais: gentil e amistoso.

- Garnet: Alienígena, que apresenta uma forma que se assemelha à de uma mulher adulta. Tem a pele negra (escura) e cabelos negros estilo black power. É alta. Possui ombros largos, cintura fina, quadris largos e coxas grossas. Na palma de uma de suas mãos tem uma pedra rubi e, na palma da outra, uma pedra safira, de onde convoca suas armas; duas manoplas em diferentes tons de vermelho, com pedras vermelhas que seriam as juntas dos dedos, enfeitadas por grandes estrelas amarelas onde ficariam as costas da mão. Usa óculos grandes, que escondem metade de seu rosto. Veste um macacão vermelho e preto, com detalhes em diferentes tons de vermelho. O macacão cobre desde seus ombros até seus pés. Não usa sapatos; usa luvas pretas que cobrem apenas seu dedo médio e vão até seus cotovelos. Garnet aparece em cinco dos cinco episódios assistidos e apresenta as seguintes características atitudinais: afetuosa, amistosa, carinhosa, corajosa, determinada, forte, inteligente, responsável, líder, calada e séria.

- Greg: É um homem adulto, baixo e gordo. Tem a pele branca. É careca no topo da cabeça; o restante do cabelo é longo, liso e castanho. Usa uma camiseta regata branca, que deixa à mostra marcas de bronzeado de uma camiseta com mangas. Num dos episódios em que 
aparece, usa uma calça de moletom cinza e não usa sapatos; nos outros, usa uma bermuda jeans, com as barras desfiadas e chinelos cinza. Greg aparece em três dos cinco episódios assistidos e apresenta as seguintes características atitudinais: afetuoso, amistoso, carinhoso, inseguro, paternal, otimista, sensível, alegre, gentil, responsável e empático.

- Lars: É um rapaz adolescente, que aparenta ter de 15 a 17 anos; tem a pele negra (clara), cabelos castanhos cacheados, cortados em estilo moicano. É alto e magro. Usa alargadores nas duas orelhas. Veste um casaco de moletom cinza, sobreposto pelo uniforme da loja onde trabalha; uma camiseta roxa, com o desenho de uma rosquinha do tipo donut no peito; calças jeans escuras, com um rasgo em um dos joelhos e tênis azuis. Lars aparece em dois dos cinco episódios assistidos e apresenta as seguintes características atitudinais: cínico, descortês, esnobe e mal-humorado.

- Opal: É uma mulher gigante, resultado da fusão de Pérola e Ametista; tem a pele lilás, longos e lisos cabelos brancos, presos em um rabo de cavalo. Carrega uma pérola na testa e uma pedra ametista no peito, de onde convoca suas armas; um arco e flecha gigante, em tons de azul e lilás. Possui quatro braços. Usa calças justas, de cor magenta e uma blusa azul com longas cortinas; calça botas amarelo-ouro. Opal aparece em um dos cinco episódios assistidos e apresenta as seguintes características atitudinais: afetuosa, alegre, amistosa, brincalhona, carinhosa, corajosa, determinada, forte, gentil, inteligente e responsável.

- Peedee: Menino que aparenta 12 anos, tem a pele branca e os cabelos amarelos em mechas, com uma espessura maior que o convencional. É magro e tem um espaço entre os dentes da frente. Veste uma camiseta regata branca e calças tipo cargo; calça sapatos amarelos. Peedee aparece em um dos cinco episódios assistidos e apresenta as seguintes características atitudinais: amistoso e responsável.

- Pérola: Alienígena, apresenta uma forma que se assemelha à de uma mulher adulta; tem a pele branca mais alva que as demais. É alta e magra. Tem cabelos curtos e lisos em um tom de rosa-pálido. Carrega uma pérola na testa, de onde convoca sua arma, uma grande lâmina azul com um cabo comprido, adornada por espirais na parte cortante. Veste uma blusa 
regata azul, com o desenho de uma pequena estrela amarela no peito; um short rosa-pálido e sapatilhas azuis, com meias de tom esverdeado. Pérola aparece em cinco dos cinco episódios assistidos e apresenta as seguintes características atitudinais: afetuosa, amistosa, carinhosa, corajosa, gentil, determinada, forte, inteligente, maternal, responsável, honesta, esnobe, pessimista, séria, impaciente e mal-humorada.

- Prefeito Dewey: É homem e adulto; tem a pele branca, cabelos castanhos curtos; usa um topete; é magro e baixo. Veste um terno cinza por cima de uma camisa branca; usa uma gravata preta e sapatos sociais na cor marrom. Prefeito Dewey aparece em um dos cinco episódios assistidos e apresenta as seguintes características atitudinais: esnobe, sério e impaciente.

- Ronaldo: É um rapaz adolescente, que aparenta ter de 15 a 17 anos. Tem a pele branca e os cabelos amarelos, em mechas grossas. É baixo e gordo. Veste uma camisa de botões vermelhos e uma bermuda cáqui, sobrepostos por um avental branco. Calça sandálias cinza e usa óculos de grau pequenos e retangulares. Ronaldo aparece em um dos cinco episódios assistidos e apresenta as seguintes características atitudinais: amistoso, criativo e entusiasmado.

- Sadie: É uma adolescente que aparenta ter de 15 a 17 anos, de pele branca e cabelos loiros ondulados na altura dos ombros. É baixa e gorda. Veste o uniforme da loja onde trabalha; uma camiseta roxa com o desenho de uma rosquinha do tipo donut no peito; uma calça preta justa e sapatos fechados vermelhos. Sadie aparece em dois dos cinco episódios assistidos e apresenta as seguintes características atitudinais: afetuosa, amistosa, carinhosa, empática, gentil e alegre.

- Steven: Menino, de aparentemente 12 anos, de pele branca e cabelos cacheados, volumosos e negros, gordo. Carrega uma pedra quartzo rosa no umbigo, de onde convoca sua arma, um escudo rosa adornado pelo desenho de uma rosa. Veste uma camiseta cor-derosa, com o desenho de uma grande estrela amarela no peito; calças azuis, com as barras dobradas, e chinelos cor-de-rosa. Steven aparece em cinco dos cinco episódios assistidos e apresenta as seguintes características atitudinais: afetuoso, amistoso, alegre, brincalhão, 
carinhoso, corajoso, gentil, inseguro, sensível, vulnerável, dramático, determinado, otimista, irresponsável, insistente e empático.

Após essa descrição minuciosa de cada personagem da série animada, passamos a pensar sobre como cada uma delas representa um tipo, ou vários tipos, de masculinidade e de feminilidade.

\section{2. "Mas se eu pudesse, eu ia querer ser uma mulher gigante..." - as discussões sobre as} feminilidades e masculinidades em Steven Universo

Neste tópico, apresentaremos as discussões advindas de nossa pesquisa, dialogando com os conceitos que nortearam nossas problematizações. Nossa proposta foi problematizar e discutir os tipos de feminilidade e masculinidade apresentados nos cinco episódios selecionados da primeira temporada da série animada Steven Universo.

Segundo Bacarin (2015, p. 39), os conceitos de feminilidade e masculinidade estão diretamente ligados ao conceito de gênero, constituindo a maneira como os sujeitos vivem e expressam o feminino e o masculino. A autora sugere que essas formas de vivência e expressão do masculino e do feminino são construídas socialmente.

Para Connel (1995, p. 118), masculinidade é a maneira como se configuram de forma prática os modos de ser homem, existindo várias configurações; por consequência, várias formas de ser homem, várias masculinidades. Podemos analisar as feminilidades também partindo dos estudos de Connel, pensando que, assim como as masculinidades, também existem diversas formas de ser mulher, de vivenciar a(s) feminilidade(s).

Louro (2007, p. 9) afirma que "as muitas formas de fazer-se mulher ou homem, [...] são sempre sugeridas, anunciadas, promovidas socialmente [...]. Elas são também, renovadamente, reguladas, condenadas ou negadas". Continuando essa discussão, a autora diz que "a inscrição dos gêneros - feminino ou masculino - nos corpos é feita, sempre, no contexto de uma determinada cultura, portanto com as marcas dessa cultura" (LOURO, 2007, p. 11). Seguindo essa perspectiva, entendemos que as identidades, e aqui se incluem as

\footnotetext{
${ }^{5}$ Parte da letra da música Mulher Gigante, cantada por Steven no episódio 12, A mulher gigante.
} 
feminilidades e masculinidades, são expressões sociais, construídas na relação com os/as outros/as, no contexto social e histórico em que o sujeito está inserido e com as outras identidades do sujeito.

Ainda recorrendo a Louro, compreendemos que existem diversas formas de viver o feminino e o masculino; entretanto, "algumas delas [...] ganham uma visibilidade e uma força tão grandes que deixam de ser percebidas como representações e são tomadas como sendo $a$ realidade" (2007, p. 16, grifo da autora). Tais representações são padronizadas, tidas como norma/padrão, e tudo que foge ou se distancia dela é tratado como desviante e errado.

A autora Sabat afirma que "estudos da masculinidade trazem à tona discussões sobre as funções sociais que os homens são obrigados a desempenhar, em nome das convenções culturais, como o sustento financeiro da família, a ascensão social ou o sucesso profissional” (2003, p. 82). Entendemos que as feminilidades são construídas na cultura da mesma forma que são construídas as masculinidades, fazendo com que as meninas e mulheres busquem desempenhar funções sociais que as aproximem da norma imposta, como ser dóceis, gentis, obedientes e amorosas (LOURO, 2000, p. 28).

Beiras et al. (2007) discutem as maneiras como as masculinidades são apresentadas nas histórias em quadrinhos (HQ's) norte-americanas. Apesar de neste artigo não tratarmos do mesmo artefato cultural analisado pelos/as autores/as, o consideramos importante para nosso estudo, uma vez que discutimos sobre os tipos de feminilidade e masculinidade apresentados em uma série animada. Os/as autores/as argumentam:

Um corpo musculoso, forte e viril (tirado de academias, imagens publicitárias e veículos de entretenimento) vem historicamente se tornando o referencial de corporeidade masculina, enquanto corpos que desviam deste padrão são comumente satirizados ou mesmo excluídos da mídia. Segundo padrões normativos da atualidade, músculos são indicativos de masculinidade [...], atestando um ideal de força e virilidade, potencializado pela mídia sobre o imaginário de jovens homens. (BEIRAS et al., 2007, p. 62).

Os/as autores/as discutem sobre os modelos hegemônicos de masculinidade e feminilidade na produção e veiculação de personagens na mídia. O masculino é representado como forte e viril e o feminino ligado à doçura e afetividade, mesmo se tratando, às vezes, de serem super-heroínas nas narrativas contadas. 
$\mathrm{Na}$ série Steven Universo, como são construídos e veiculados os tipos de masculinidade e feminilidade? Há novas formas de se constituir como masculino e feminino? Ou há o mesmo do mesmo, ou seja, a reiteração da norma de gênero com a constituição de identidades de gênero parecidas e referenciadas pela normatividade?

Em nossa análise e discussão das informações coletadas e analisadas na perspectiva da etnografia de tela, percebemos não haver uma resposta binária para essas questões, ou seja, não há isso ou aquilo, e sim isso $e$ aquilo. Este é um aspecto importante a se ressaltar, por se tratar de uma série de tamanha audiência e por quebrar alguns dos estereótipos socialmente tão sacralizados.

A série Steven Universo rompe com a perspectiva de um modelo único de masculinidade ao apresentar como personagem principal um menino que não corresponde aos ideais sociais e culturais de masculinidade. A série traz como herói uma criança, gorda, em situação de aprendiz, que demonstra vulnerabilidade e insegurança em diversos momentos e que possui uma arma de defesa, um escudo, inútil para ataques, servindo como instrumento para a própria proteção e a de seu grupo.

Outra personagem masculina de destaque na série é Greg Universo, pai do protagonista Steven. Greg apresenta características atitudinais também relacionadas culturalmente à feminilidade, como carinho, afeto, insegurança, sensibilidade e gentileza. Ademais, Greg configura a figura paterna na série.

Moreira e Toneli discutem as questões da paternidade: “[...] atrelada à divisão sexual do trabalho, a paternidade se fundia à capacidade de prover financeiramente a família, independentemente da relação concreta do pai com seus filhos e filhas" (MOREIRA; TONELI, 2013, p. 390). Greg rompe com esse modelo de paternidade. Ele não é financeiramente responsável por Steven, nem por nenhuma outra família; contudo, tem responsabilidade afetiva para com seu filho, sendo encarregado de mediar conhecimentos e configurando uma pessoa adulta na qual Steven pode confiar em situações de perigo, demonstrando uma postura de cuidados e afetos. Uma nova masculinidade e uma nova paternidade se configuram com a imagem e as atitudes do pai do protagonista da série. 
As personagens masculinas de menor destaque na série - Cebola, Fryman, Lars, Peedee, Prefeito Dewey e Ronaldo - apresentam características atitudinais que se aproximam e se distanciam da norma cultural de masculinidade. Três deles (Fryman, Peedee e Ronaldo) são apresentados como pessoas amistosas e gentis. Cabe aqui uma atenção especial à personagem Fryman, que, fisicamente, corresponde à norma de masculinidade já citada, sendo um homem branco, alto, musculoso e que usa barba, o que contrasta com suas características atitudinais, sendo apresentado como gentil e amistoso, características culturalmente associadas à feminilidade.

As outras três personagens masculinas (Cebola, Lars e Prefeito Dewey) apresentam características físicas e atitudinais que se aproximam da norma de masculinidade construídas social e culturalmente, como descortesia - nos casos das personagens de Cebola e Lars -, seriedade e hombridade - no caso do Prefeito Dewey. O prefeito apresenta-se fisicamente como homem de sucesso; é um homem branco, veste-se com terno e gravata e sapatos sociais. Sua aparência demarca a posição social de superioridade: homem, branco e bem-sucedido.

E os tipos de feminilidade na série? Como são as personagens representadas?

Sobre as representações de feminilidade nos desenhos animados ao longo da história, Mendes elucida:

\begin{abstract}
Primeiramente relegadas a papéis secundários nas tramas, passaram a ter destaque e até mesmo a protagonizar histórias de heroísmo pouco a pouco, com a força da terceira onda do movimento feminista [...]. Quando surgiram as grandes personagens mulheres nas animações, eram em sua maioria princesas, sem muitas qualidades ou ocupações que não fossem o cuidado com a beleza e com a vida doméstica. Posteriormente, ainda que perdessem a realeza, tais personagens eram marcadas pelas características culturalmente atribuídas ao gênero feminino. (MENDES, 2016, p. 1-2).
\end{abstract}

A autora traz uma perspectiva histórica das personagens femininas nos desenhos animados, relegadas a papéis secundários e/ou subalternos, mesmo quando protagonistas. Cumprindo com as normas de gênero impostas social e culturalmente e sempre correspondendo ao ideal de beleza e feminilidade, as personagens ainda são representadas com características do tipo: "magra, pele branca, cabelos longos e loiros, olhos azuis, jovem, saudável, sem nenhum tipo de doença ou deficiência física e, evidentemente, heterossexual” (BACARIN, 2015, p. 100). 
Neste ponto, a série Steven Universo apresenta novas rupturas com as imagens de feminilidade veiculadas pela mídia, enquanto, em outros pontos, se aproxima. As personagens femininas de destaque da série (Ametista, Garnet e Pérola) apresentam características culturalmente atribuídas a personagens masculinas, como força, inteligência e coragem. Sem cair, porém, em um binarismo, as personagens femininas não apresentam características "masculinas" em detrimento das "femininas"; elas não são uma coisa ou outra, mas um conjunto de características que se complementam, passeando entre aspectos que se aproximam e se distanciam do já citado padrão ou tipo de feminilidade.

As personagens femininas aproximam-se do ideal de beleza de diferentes formas: Pérola, Garnet e Opal são magras e têm cinturas demarcadas; Pérola e Sadie são brancas; Sadie é loira; Pérola, Ametista e Opal têm cabelos lisos. É possível notar que em cada uma das personagens femininas existe pelo menos uma característica que a aproxima da norma de feminilidade, branquitude e do ideal de beleza veiculados pela mídia e construídos culturalmente.

Percebemos uma ambiguidade nos tipos de feminilidade e masculinidade apresentados nos episódios assistidos, enquanto algumas personagens, como Greg e Steven, distanciam-se grandemente das normas de gênero impostas ou predominantes, revelando uma nova perspectiva de vivência da masculinidade, outras, como Prefeito Dewey, reforçam a maneira hegemônica de ser homem.

É possível notar essa ambiguidade ainda mais fortemente nas personagens femininas, que, em sua maioria, apresentam características atitudinais culturalmente atribuídas social e culturalmente à masculinidade, porém, não deixam de apresentar características como gentileza e afeto, aspectos muito ligados ao feminino. Temos ainda a questão corporal, como já salientado: todas as personagens femininas, de alguma forma, aproximam-se do ideal de beleza - um corpo jovem, magro, branco e de cabelos lisos.

\section{CONSIDERAÇÕES FINAIS}


Iniciamos esta pesquisa tendo como foco estudar os tipos de feminilidade e masculinidade na primeira temporada da série animada Steven Universo, com o objetivo de discutir e problematizar as feminilidades e masculinidades por ela veiculadas. Face às nossas discussões, pensamos não haver uma única maneira de olhar para a questão.

Ao assistir repetidas vezes aos episódios selecionados, demo-nos conta das inúmeras possibilidades de questionamento e problematização. Personagens femininas e masculinas e suas características físicas e atitudinais são apenas alguns dos pontos problematizados; muitas outras questões, além das que nos propusemos nesta pesquisa, podem ser discutidas.

Os episódios selecionados apresentam personagens femininas e masculinas que rompem com os padrões de feminilidade e masculinidade hegemônicos e em parte os fundem, tornando possíveis diferentes leituras e diferentes óticas, provocando, junto a quem assiste ao desenho, tanto conformidade quanto resistência.

Em nossas discussões e leituras e ao assistir aos episódios selecionados, pudemos ponderar que o desenho animado, enquanto artefato cultural, ensina diferentes formas de ser homem/menino e mulher/menina como integrantes do processo de constituição dos sujeitos. Os diferentes artefatos culturais, por atuarem/interagirem no processo de formação de nossas identidades, nos permitem nos apropriar de algo pensado e externalizado pela cultura. Por essa razão, faz-se necessário pensar, discutir e problematizar que padrões de feminilidade e masculinidade estão sendo veiculados às crianças na mídia. Esta pode ser uma poderosa forma de discutir com as próprias crianças os diversos artefatos culturais e de como eles promovem ou reiteram formas de viver modos de ser masculinos e femininos, além de outros assuntos de interesse das crianças, que nem sempre encontram espaço para tais discussões e reflexões.

\section{REFERÊNCIAS}

BACARIN, Telma Iara. FILMES DE ANIMAÇÃO DA BARBIE: normatizações e resistências aos modelos de feminilidade. 2015. 204 f. Dissertação (Mestrado em Educação) - 
programa de pós-graduação em educação do campus do Pantanal - PPGE/CPAN, Universidade Federal de Mato Grosso do Sul, Corumbá. 2015.

BALESTRIN, Patrícia; SOARES, Rosângela. Etnografia de tela": uma aposta metodológica. In: MEYER, Dagmar Estermann; PARAÍSO, Marlucy Alves. Metodologias de pesquisas póscríticas em educação. Belo Horizonte: Mazza Edições, 2012.

BEIRAS, Adriano et al. Gênero e super-heróis: o traçado do corpo masculino pela norma. Psicologia \& Sociedade, $\quad$ v. 19, n. 3, 2007. Disponível em: < http://www.scielo.br/pdf/psoc/v19n3/a10v19n3>. Acesso em 16 de outubro de 2017.

CONNEL, Robert. Políticas da masculinidade. In: Educação \& Realidade. Porto Alegre, v. 20, $\mathrm{n}^{\mathrm{o}} \quad 2, \quad$ jul./dez., 1995, p. 185-206. Disponível em: < https://repositorio.ufsc.br/bitstream/handle/123456789/1224/connel_politicas_de_masculinidade. pdf?seq>. Acesso em 19 de outubro de 2017.

DA SILVA, Tomaz Tadeu. Teoria cultural e educação: um vocabulário crítico. Belo Horizonte: Autêntica, 2000.

ESPÍNDULA MOREIRA, Lisandra; FILGUEIRAS TONELI, Maria Juracy. Paternidade responsável: problematizando a responsabilização paterna. Psicologia \& Sociedade, v. 25, n. 2, 2013. Disponível em: < http://www.redalyc.org/html/3093/309328218016/>. Acesso em 16 de outubro de 2017.

FELIPE, Jane. Infância, gênero e sexualidade. In: Educação \& Realidade, v. 25, n. 1, 2000.

Gênero e sexualidade nas pedagogias culturais: implicações para a educação infantil. 1995. Disponível em: http://www.titosena.faed.udesc.br/Arquivos/Artigos_gensex/SexualidadeInfantil.pdf $>$. Acesso em 14 de outubro de 2017.

LOURO, Guacira Lopes. Gênero, sexualidade e educação. Lisboa, PT: Porto Editora, 2000.

Gênero, sexualidade e educação: uma perspectiva pós estruturalista. Petrópolis: vozes, 2008. 
. Pedagogias da sexualidade. In: LOURO, Guacira Lopes (Org). O corpo educado: pedagogias da sexualidade. Belo Horizonte: Autêntica, 2007. p. 7-34.

MENDES, Mônica Vitória dos Santos. A construção das imagens que nos constroem: marcas de gênero no corpo feminino representado em desenhos animados. In: XXXIX Congresso Brasileiro de Ciências aa Comunicação. São Paulo: 2016. Disponível em: $<$ http://portalintercom.org.br/anais/nacional2016/resumos/R11-0706-1.pdf $>$. Acesso em 11 de outubro de 2017.

MEYER, Dagmar Estermann; PARAÍSO, Marlucy Alves (Orgs.). Metodologias de pesquisas pós-críticas em educação. Belo Horizonte: Mazza Edições, 2012.

RIAL, Carmen. Antropologia e mídia: breve panorama das teorias de comunicação. Florianópolis: UFSC, 2004. Disponível em: < http://apm.ufsc.br/files/2015/05/74.carmen-midia.doc>. Acesso em 14 de novembro de 2017.

SABAT, Ruth. Filmes infantis e a produção performativa da heterossexualidade. Porto Alegre/RS: UFRGS, 2003. Tese de Doutorado. Disponível em: $<$ http://www.lume.ufrgs.br/handle/10183/3757>. Acesso em 17 de outubro de 2017.

SALIN, Sara. A linguagem. In: SALIN, Sara. Judith Butler e a teoria Queer. Belo Horizonte: Autêntica, 2012. p. 134-164.

SEVILLA, Gabriela Garcia. Pedagogias de gênero e sexualidade em artefatos culturais: reflexões sobre uma experimentação. In: Reunião da Anped, 4, 2015. Disponível em: < http://37reuniao.anped.org.br/wp-content/uploads/2015/02/ Trabalho-GT23-4463.pdf>. Acesso em 17 de outubro de 2017.

STEINBERG, Shirley; KINCHELOE, Joe. Sem segredos: cultura infantil, saturação de informação e infância pós moderna. In: STEINBERG, Shirley; KINCHELOE, Joe (Org). Cultura infantil: a construção corporativa da infância. Rio de Janeiro: Civilização Brasileira, 2001. p. 9-49.

\section{EPISÓDIOS ANALISADOS DA SÉRIE STEVEN UNIVERSO}


A MULHER gigante. Direção: Joe Johnston e Jeff Liu. In: Steven Universo (1 ${ }^{\mathrm{a}}$. temporada). Direção: Rebecca Sugar. Burbank: Cartoon Network, 2014. 11m32s, color. Título original: Giant woman.

DEDOS de gato. Direção: Hilary Florido, Ian Jones Quartey, Kat Morris e Rebecca Sugar. In: Steven Universo (1 $1^{\mathrm{a}}$. temporada). Direção: Rebecca Sugar. Burbank: Cartoon Network, 2014. $11 \mathrm{~m} 32 \mathrm{~s}$, color. Título original: Cat fingers.

NEGOCIANDO com o Cebola. Direção: Lamar Abrams. In: Steven Universo (1 ${ }^{\mathrm{a}}$. temporada). Direção: Rebecca Sugar. Burbank: Cartoon Network, 2014. 11m32s, color. Título original: Onion trade.

O BRILHO da pedra. Direção: Joe Johnston e Jeff Liu. In: Steven Universo (1 ${ }^{\mathrm{a}}$. temporada). Direção: Rebecca Sugar. Burbank: Cartoon Network, 2014. 11m32s, color. Título original: Gem glow.

O CANHÃO de laser. Direção: Kat Morris e Rebecca Sugar. In: Steven Universo (1 ${ }^{\mathrm{a}}$. temporada). Direção: Rebecca Sugar. Burbank: Cartoon Network, 2014. 11m32s, color. Título original: Laser Light Cannon. 